
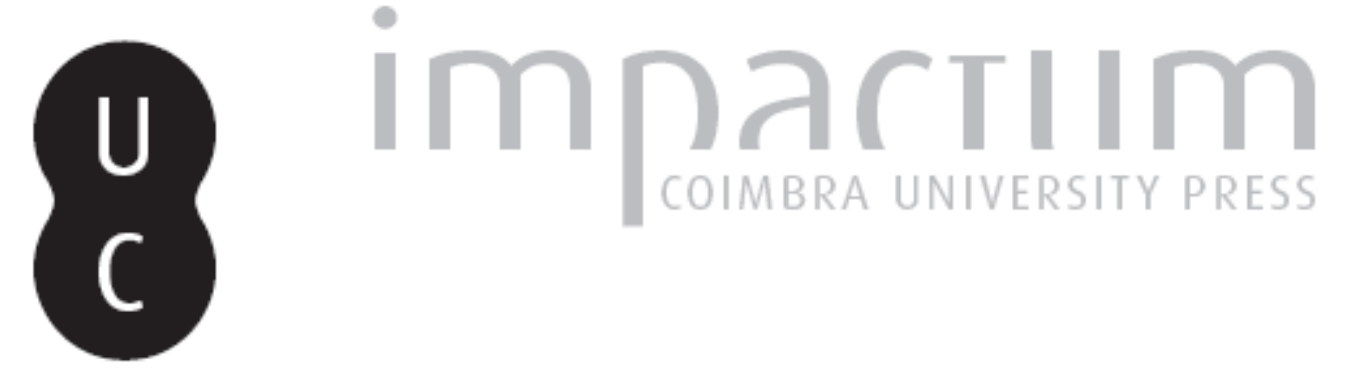

\title{
Uma cupa funerária da Vidigueira
}

\section{Autor(es): Lopes, Maria da Conceição}

Publicado por: Imprensa da Universidade de Coimbra

URL persistente:

URI:http://hdl.handle.net/10316.2/45619

DOI:

DOI:https://dx.doi.org/10.14195/1647-8657_25_13

Accessed : $\quad$ 26-Apr-2023 12:55:06

A navegação consulta e descarregamento dos títulos inseridos nas Bibliotecas Digitais UC Digitalis, UC Pombalina e UC Impactum, pressupõem a aceitação plena e sem reservas dos Termos e Condições de Uso destas Bibliotecas Digitais, disponíveis em https://digitalis.uc.pt/pt-pt/termos.

Conforme exposto nos referidos Termos e Condições de Uso, o descarregamento de títulos de acesso restrito requer uma licença válida de autorização devendo o utilizador aceder ao(s) documento(s) a partir de um endereço de IP da instituição detentora da supramencionada licença.

Ao utilizador é apenas permitido o descarregamento para uso pessoal, pelo que o emprego do(s) título(s) descarregado(s) para outro fim, designadamente comercial, carece de autorização do respetivo autor ou editor da obra.

Na medida em que todas as obras da UC Digitalis se encontram protegidas pelo Código do Direito de Autor e Direitos Conexos e demais legislação aplicável, toda a cópia, parcial ou total, deste documento, nos casos em que é legalmente admitida, deverá conter ou fazer-se acompanhar por este aviso.

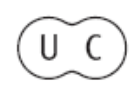


FACULDADE DE LETRAS

INSTITUTO DE ARQUEOLOGIA

CONIMBRIGA

$V O L U M E X X V$

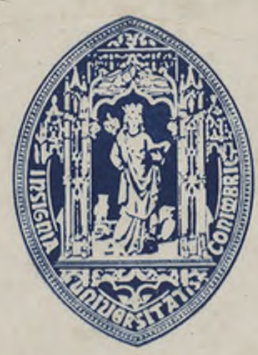

UNIVERSIDADE DE COIMBRA

1986 
MARIA DA CONCEIÇ̃̃o LOPES

Licenciada em História (variante Arqueologia)

UMA CUPA FUNERÁRIA DA VIDIGUEIRA

«Conimbriga», XXV (1986), p. 205-212

Resumo: Estuda-se uma cupa inédita proveniente do Monte das Fontes,

Selmes, Vidigueira. Trata-se, mais uma vez, do monumento funerário dum liberto.

A forma como o dedicante se coloca perante o dedicado faz duma inscrição de libertus — assaz espalhada na região de Pax Iulia - um importante documento acerca das relações sociais na época.

RéSumé: Étude d'une cupa inédite trouvée au Monte das Fontes - Selmes, Vidigueira. Il s'agit, encore une fois, du monument funéraire d'un affranchi.

La façon dont le dédiant se place face au dédié fait d'une inscription de libe?'tus — assez répandue dans la région de Pax Iulia - un important document sur les rapports sociaux de l'époque. 
(Página deixada propositadamente em branco) 


\section{UMA CUPA FUNERÁRIA DA VIDIGUEIRA}

É elevado o número de vestígios da ocupação romana por nós detectados no concelho de Vidigueira $\left({ }^{\mathrm{x}}\right)$.

Com o estudo da sua distribuição, a que oportunamente nos referiremos, pensamos contribuir para a compreensão de como foi a implantação rural nas zonas limítrofes de Pax Iulia.

De momento, interessa-nos dar a conhecer mais um importante monumento epigráfico que, juntamente com uma ara funerária recolhida por Vasco Mantas no Monte de Pontinha - Selmes ( $\left.{ }^{2}\right)$, constituem, até agora, os únicos documentos escritos romanos aqui encontrados.

Trata-se de um fragmento de cupa, em mármore azulado de Trigaches, encontrado no Monte das Fontes - Pedrógão - Vidigueira (3) (Fig. 1).

Ainda que junto à casa do monte sejam visíveis alguns materiais de construção da época romana (tegulae, lateres), o monumento não se encontrava integrado em contexto arqueológico, estando, no momento em que o identificámos, no casão do monte.

Fracturada no seu lado direito, a cupa conserva apenas $78 \mathrm{~cm}$. de largura.

I $\left.^{1}\right)$ Referimo-nos, de modo particular, a parte oriental do concelho, zona em que fizemos incidir o nosso trabalho de carta arqueológica.

(2) José d'ENCARNAÇÃo, Inscrições Romanas do Conventus Pacensis (= IRGP), Coimbra, 1984, n. ${ }^{\circ} 333 \mathrm{a}$.

(3) C. M. 1/25.000, Serviços Cartográficos do Exército, Lisboa, 1965 FL. 500; Latitude 239,5 Longitude 132,25. 
Observando-a na sua largura total visivel, verificam-se, à esquerda, dois traços gravados representando um arco de aduela; distanciado $23,5 \mathrm{~cm}$ e $36,5 \mathrm{~cm}$, o mesmo esquema representa o segundo e terceiro arcos de aduela, respectivamente.

Falta à cupa toda a parte direita; contudo, pensamos poder reconstituí-la por simetria com a parte esquerda intacta.

$\mathrm{O}$ espaço entre a extremidade e o primeiro arco de aduela é de $6 \mathrm{~cm}$, o arco tem $4 \mathrm{~cm}$ e o espaço entre este e o segundo arco é $23,5 \mathrm{~cm}$, o que, totalizando $33,5 \mathrm{~cm}$, dava muito provavelmente, uma largura de $111,5 \mathrm{~cm}$.

Truncada na parte inferior, a altura no topo esquerdo é $17,5 \mathrm{~cm}$. Esta parte recebeu uma decoração feita de um sulco circular, de uma haste vertical e dois segmentos de recta simétrica em relação ao eixo central.

$O$ corte feito no sentido da altura, na parte direita, teve em vista um reaproveitamento como pedra de lagar, como sugere o entalhe rectángulo-trapezoidal de $10 \mathrm{~cm}$ de altura e $7 \mathrm{~cm}$ de largura.

A inscrição está colocada ao centro da cupa, no dorso.

$\mathrm{O}$ campo epigráfico é limitado, à esquerda e à direita, pelos $\operatorname{arcos}$ de aduela centrais; pode pensar-se que, originalmente, uma linha horizontal limitava superiormente o campo epigráfico, mas a forma irregular como essa linha se inclina para a esquerda inviabiliza a hipótese de qualquer desenho voluntário, o mesmo se passando com o traço sob a 1. 3. O mármore de Trigaches é bastante frágil, apresentando muitas vezes fracturas deste tipo. Inferiormente, a inscrição terminaria após o último espaço interlinear.

Dimensões: $78(111,5) \times 38$ x17.

Campo epigráfico: $31,7 \times 36,5$.

D (is) . M(anibus) . S (aerum) /1 (ulius). HILARIVS / AN\{norum) XXVIII (viginti octo) I LIBERTO . ME/RENTI PATRO $/ 5 \mathrm{~N}\left({ }^{\wedge}\right)$. $\mathrm{P}($ osuit $) . \mathrm{H}($ ic $)$. $\mathrm{S}($ itus $) . \mathrm{E}\{$ st $)$. $\mathrm{S}($ it $) . \mathrm{T}($ ibi $) . \mathrm{f}\{$ erra $)$. L(evis) .

Consagrado aos deuses Manes. Aqui jaz Júlio Hilário, de 28 anos. O patrono colocou ao liberto digno de mérito. 
Altura das letras: 1. 1: 1,9; 1. 2: 2,7; 1. 3: 2,7; 1. 4: 2,7/3,7; 1. 5: 3,7. Espaços: 1: 1,4; 2: 1,23; 3: 1,4/1,25; 4 e 5: 1,4 .

A paginação é feita segundo um eixo de simetria com alinhamento à esquerda, salvo na 1.1 .

À direita, existe um alinhamento entre as linhas 3,4 e 5 , estando a 1. 2 recuada e a 1.6 avançada. Saliente-se a tendência para apresentar o texto sob a forma de «caixa».

Os caracteres acusam uma inclinação à esquerda; são de tipo capital quadrada, com franca influência actuária (talvez motivada por uma ordinatio desenhada a pincel); $\mathrm{M}$ bastante aberto; $\mathrm{R}$ de alça breve e haste oblíqua longa; $\mathrm{B}$ assimétrico, de pança inferior maior; T com haste curva; A largo com barra na parte superior.

A pontuação é feita por pontos triangulares.

No geral, é uma epígrafe harmoniosa, ainda que o seu tratamento não seja de superior qualidade.

A análise directa da pedra e a fotografia permitem reconstituir sem dificuldade o que desapareceu do texto: na 1. 5, a seguir ao $\mathrm{R}$ de merenti, podem ver-se o $\mathrm{E}$, traços do $\mathrm{N}$, a parte superior do I, a alça do $\mathrm{P}$ e a haste do T. Na 1. 6, dois traços definem parte do $\mathrm{N}$, a haste vertical do $\mathrm{P}$, e os traços verticais do H são ainda reconhecíveis (Fig. 2).

$\mathrm{O}$ texto memora um membro da gens Iulia. «O gentilicio Iulius ocupa lugar cimeiro entre os representados na Hispânia. A sua grande difusão na Lusitânia ficou a dever-se, fundamentalmente, a liberalidades de César e de Augusto, os quais agregaram à gens Iulia uma multidão de famílias de origem étnica diversa» $\left.{ }^{4}\right)$. No conventus Pacensis, os Iulii encontram-se representados em 112 inscrições, alguns deles como gente de condição social importante(õ). A menção do gentilicio em sigla pode significar a grande difusão que este conhecia, bem como o hábito de identificar uma personagem pelo seu cognome.

(4) Vasco Mantas, Inscrições Romanas do Museu de Torres Vedras, «Conimbriga», XXI, 1984, p. 11.

(5) IRCP 382. 
Hilarius é um cognome pouco representado; no conjunto do C7L, Kajanto encontra apenas referidos três homens e oito mulheres com esce nome, sendo uma de condição liberta $\left(^{6}\right)$.

A fraca representação deste cognome no mundo romano, desconhecido na Península Ibérica até ao presente, leva-nos a admitir que se trate de uma forma tardia do cognome Hilarus, conhecido na Península por seis inscrições da Tarraconense $\left({ }^{7}\right)$, três na Bética $\left(^{8}\right)$ e uma na Lusitânia $\left(^{9}\right)$.

No conventus Pacensis apenas se conhece a forma aparentada, Hilarianus $\left({ }^{10}\right)$.

Kajanto ( $\left.{ }^{n}\right)$ inclui estes cognomes no grupo cuja origem se relaciona com traços de carácter e salienta a sua etimologia grega e a qualidade de escravos e libertos da maioria dos assim denominados.

Não sendo inédita na epigrafia latina e particularmente no conventus Pacensis a referência aos merecimentos de alguém (12), sublinhe-se o facto de neste caso ser o patrono que, omitindo o seu nome, perpetua a memória do liberto.

É por demais confirmada a permeabilidade a relações amigáveis entre gentes de condição social diferente, mas quase sempre é o de condição inferior a elogiar o outro. $\mathrm{E}$ em duas inscrições do conventus, o patrono perpetua o seu liberto mas identifica-se com o nome $\left({ }^{13}\right)$.

Não nos custa admitir que estejamos perante um liberto cujo comportamento, fidelidade e dedicação fossem exemplares, merecendo por isso uma homenagem do seu patrono (14), que escusa

$\left(^{6}\right)$ Iiro Kалаnто, The Latin cognomina, Helsínquia, 1965, p. 260 (= KaJanto, Cognomina $)$.

( $\left.{ }^{7}\right)$ ILER 1311, 4111, 4844, 5639, 6087, 6475.

(8) ILER 3123, 4727, 5006.

( $\left.{ }^{9}\right)$ ILER 4890.

(10) IRCP 260. Na Península apenas se repete mais uma vez, numa inscrição honorífica da Tarraconense.

(n) Kajanto, Cognomina, p. 68, 69; não esqueçamos que Hilarus é um dos libertos de Cícero, FAM. XIII, 33.

(12) IRCP 106, 114, 181, 313, 333, 361, 399, 429.

(13) IRCP 98, 333.

(14) Acerca dos elogia que os patronos fazem aos libertos, cf. G. Fa B RE, Libertus - Recherches sur les rapports patrons-affranchis à la fin de la République 
o seu nome, quiçá por ser imediatamente identificado, ao ser feita menção ao seu liberto.

No conjunto dos 101 libertos identificados no conventus, este Hilarius é alguém «importante», pois o seu patrono não só omite o nome como permite que o seu estatuto seja dividido por duas linhas, salientando o nome do liberto que preenche uma linha $\left({ }^{15}\right)$.

A análise paleográfica, a invocação aos deuses Manes, o uso do adjectivo merenti, o gentilicio em sigla e a indicação da idade permitem situar o monumento no final do século $n$, início do século ui.

Esta inscrição funerária - pelo seu formulário, D.M.S., H.S.E., S.T.T.L. - integra-se numa série bem conhecida no conventus Pacensis. Estas fórmulas, banais para a região (16), foram gravadas numa cupa cuja forma se inscreve no conjunto dos monumentos epigráficos funerários da região de $\operatorname{Beja}\left({ }^{17}\right)$ — presença de $\operatorname{arcos}$ de aduela, campo epigráfico colocado ao centro, forma de tonel quase completa -, tudo apontando para a vulgarização de um modelo cuja oficina se localizaria na capital do conventus, como o sugere a presença destes monumentos $\left({ }^{18}\right)$.

Com uma cupa se honram defuntos de todas as categorias sociais; por um rito funerário, por uma cupa, desejavam os libertos assimilar-se totalmente aos ingénuos.

No caso presente, pode perguntar-se se a cupa não estaria colocada no recinto funerário consagrado à família do patronus ${ }^{(19)}$, que parece ter sido o próprio a colocá-la \{posuit).

Romaine (Coll. École Franc, de Rome, 50) Rome, 1981, s. v. elogia, p. 411. (= FABRE).

(15) No Conventus Pacensis registam-se dois casos de homenagem prestada pelos patronos a libertos, embora em ambos os exemplos eles se identifiquem pelos seus nomes (IRCP 98, 333).

(16) Para D.M.S.: IRCP 40; H.S.E.: IRCP 37; S.T.T.L.: IRCP 40.

(17) Dos 66 encontrados com inscrição funerária, 26 são cupae.

(18) Os mapas 2 e 3 que Encarnação apresenta mostram que a dispersão das cupae é limitada e que coincide com a dos monumentos feitos em mármore de Trigaches.

(19) FABRE, p. 146-147. 
Assim este monumento dá-nos um testemunho inegligenciável sobre as estruturas sociais, as práticas funerárias e ainda sobre a reutilização deste monumentos (neste caso, como peso de lagar) talvez numa época bastante próxima daquela que vulgarizou as cupae como perpetuação de gentes e virtudes. 


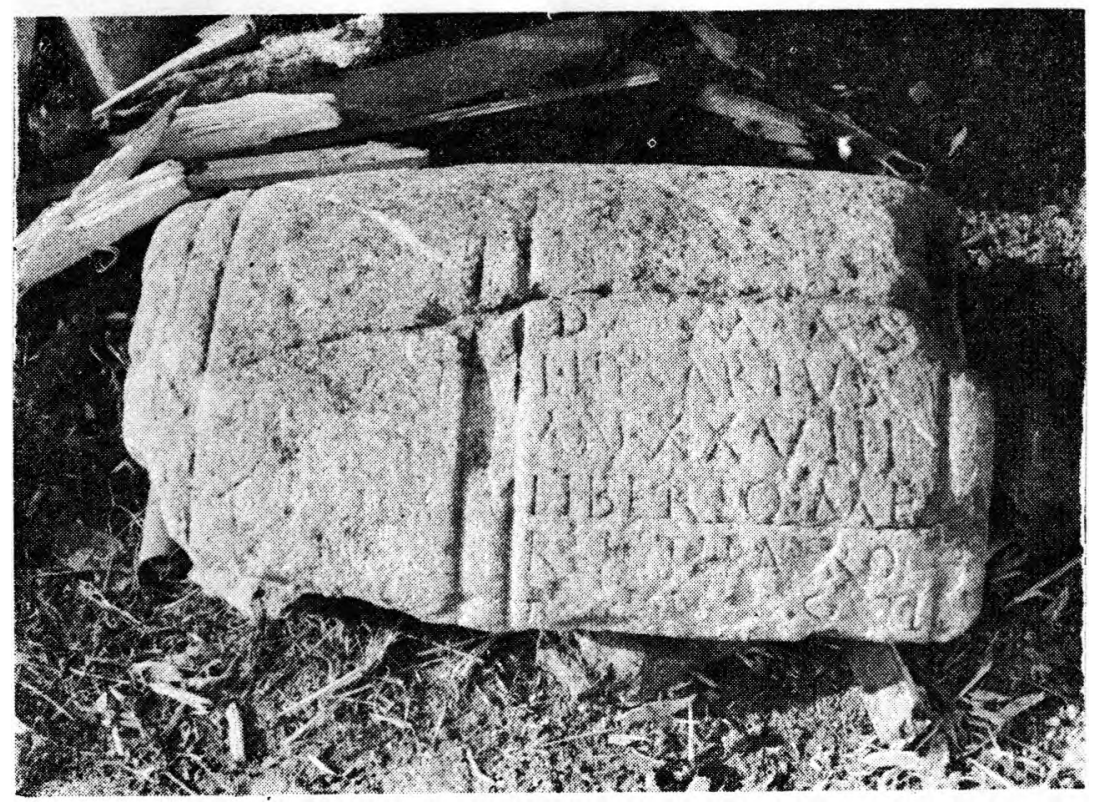

FIG. 1 -Fragmento de cupa. 


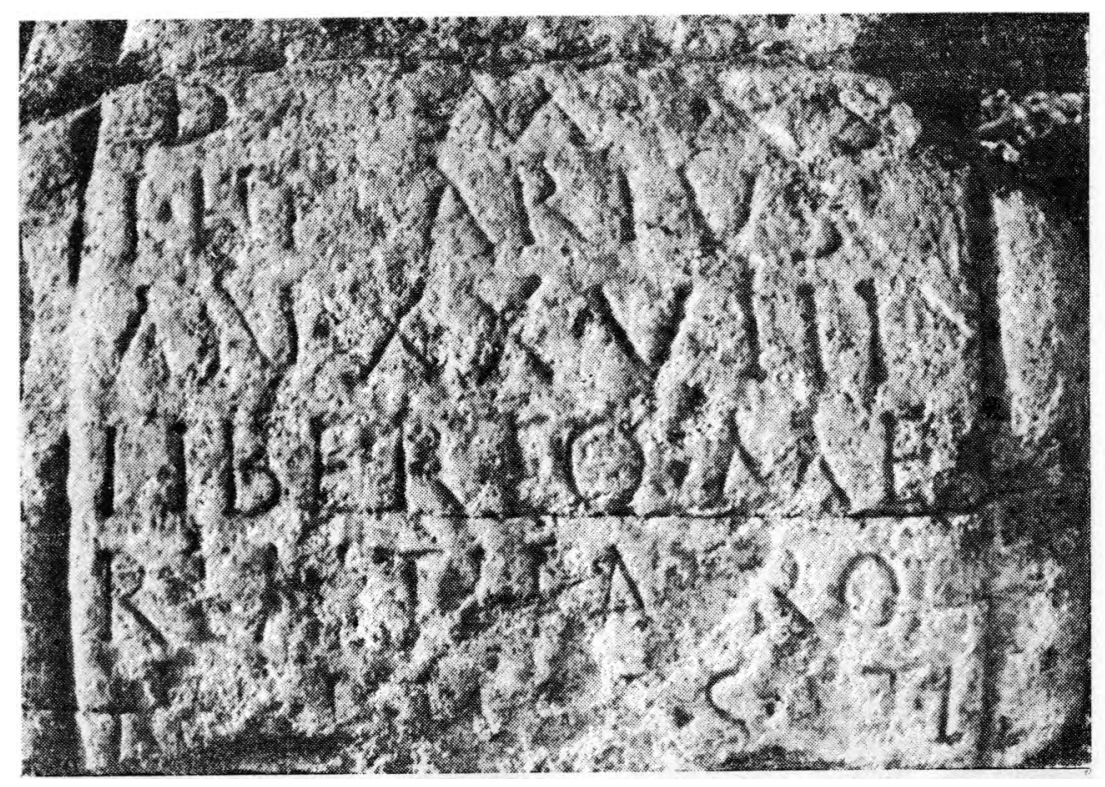

F IG. 2-Campo epigráfico. 